\begin{tabular}{|c|c|}
\hline Title & Predominant prevalence of arterial thrombosis in Japanese patients with antiphospholipid syndrome \\
\hline Author(s) & $\begin{array}{l}\text { Fuji ieda, Y uichiro; A tsumi, Tatsuya; A mengual, Olga; Odani, Toshio; Otomo, Kotaro; Kato, Masaru; Oku, Kenji; Kon, } \\
\text { Y uji iro; Horita, Tetsuya; Y asuda, Shinsuke; Koike, T akao }\end{array}$ \\
\hline Citation & $\begin{array}{l}\text { Lupus, 21(14), 1506-1514 } \\
\text { https://doi.org/10.1177/0961203312458469 }\end{array}$ \\
\hline Issue Date & $2012-12$ \\
\hline Doc URL & http:/hdl.handle.net/2115/54013 \\
\hline Rights & $\begin{array}{l}\text { The final, definitive version of this paper has been published in Lupus, 21(14), Dec. } 2012 \text { by SA GE Publications Ltd, } \\
\text { All rights reserved. } \odot 2012 \text { SA GE Publications }\end{array}$ \\
\hline Type & article (author version) \\
\hline File Information & Lup21-14_1506-1514.pdf \\
\hline
\end{tabular}

Instructions for use 


\section{Predominant prevalence of arterial thrombosis in Japanese patients with the Antiphospholipid Syndrome}

Yuichiro Fujieda MD, Tatsuya Atsumi MD PhD, Olga Amengual MD PhD, Toshio Odani MD, Kotaro Otomo MD, Masaru Kato MD PhD, Kenji Oku MD $\mathrm{PhD}$, Yujiro Kon MD PhD, Tetsuya Horita MD PhD, Shinsuke Yasuda MD $\mathrm{PhD}$ and Takao Koike MD PhD.

Department of Medicine II, Hokkaido University Graduate School of Medicine, Sapporo, Japan.

Corresponding author:Tatsuya Atsumi, MD, PhD, Department of Medicine II, Hokkaido University Graduate School of Medicine, N15 W7, Kita-ku, Sapporo 060-8638, Japan.

Telephone: $\quad+81-11-706-5915$
Fax: $\quad+81-11-706-7710$
E-mail address: $\quad$ at3tat@med.hokudai.ac.jp

Short title: APS Japanese cohort

Key words: arterial thrombosis, venous thrombosis, obstetric complications, antiphospholipid antibodies, lupus anticoagulant, anticardiolipin antibody, phosphatidylserine dependent antiprothrombin antibody

Word count: 3755words 


\section{Abstract}

Objective: To study the clinical and immunological manifestations of the antiphospholipid syndrome (APS) in Japanese population by a single center registration.

Methods: In this retrospective cohort study, 141 consecutive patients with APS, fulfilling the Sydney revised Sapporo criteria for definite APS, who visited to our Autoimmune Clinic from 1988 to 2010 were recruited and followed up. All the patients were interviewed and underwent a general physical examination by qualified rheumatologists on the day of blood sampling.

Results: $\quad$ The population comprised 119 woman and 22 men with a mean age at diagnosis of 44 years (range 11-83 years). Seventy patients (49.6 \%) had primary APS, and 71 (50.4 \%) had systemic lupus erythematosus. The prevalence of thrombosis was $85.8 \%$, arterial thrombosis found in 93 patients $(66.0 \%)$ and venous thrombosis in 46 (32.6\%). The most common thrombosis was cerebral infarction [86/141 (61.0\%)] followed by deep vein thrombosis [33/141 (23.4 \%)]. Among 70 pregnant women, $45(64.3 \%)$ had obstetric complications. Lupus anticoagulant was detected in 116 patients (82.3\%), anticardiolipin antibodies in $83(58.9 \%)$, anti $\beta 2$ Glycoprotein I antibodies in 73 (51.8\%), and phosphatidylserine-dependent antiprothrombin antibodies in 98 (69.5\%).

Conclusion: High prevalence of arterial thrombosis was noted in Japanese patients with APS. The profile of heterogeneous and complex clinical 
manifestations in was substantiated in Japanese patients with APS.

\section{Introduction}

The antiphospholipid syndrome (APS) is an autoimmune disorder characterized by widespread arterial and venous thrombosis together with adverse pregnancy history and associated with the persistent presence of antiphospholipid antibodies (aPL)1.

Antiphospholipid antibodies are a heterogenous group of circulating immunoglobulins which are usually detected by their binding to immobilized anionic phospholipids in solid phase enzyme-linked immunosorbent assays (ELISA), termed anticardiolipin antibodies (aCL) ${ }^{2}$ or by their ability to prolong the clotting time of phospholipid-dependent coagulation assays, namely lupus anticoagulant (LA) ${ }^{3}$. Although the original concept of aPL considers that those antibodies are directed against anionic phospholipids, evidence shows that the antigenic specificities of aPL include phospholipid-bound plasma proteins such as $\beta 2$ Glycoprotein I ( $\beta 2 \mathrm{GPI})^{4-6}$ or prothrombin ${ }^{7}$.

Since the first description of APS in $1983^{8}$, the range of features associated with aPL has considerably increased. APS may present with heterogeneous clinical symptoms and laboratory manifestations. In addition, APS is relatively rare and therefore, it has been difficult to carry out epidemiological studies. Additional factors such as the diversity in the definition of the variables and the lack of standardization of laboratory tests 
may influence the results of those studies.

In 1999, the preliminary classification criteria for APS (Sapporo criteria) were published ${ }^{9}$. Based on those criteria, Cervera et al ${ }^{10}$ reported the clinical and immunological manifestations of 1000 European patients with APS. This multicenter international study included patients from 13 countries and provides different patterns of disease expression in a large cohort of patients with APS.

Since the publication of Sapporo criteria, new clinical, laboratory and experimental insights on APS were addressed. A preconference workshop, preceding the $11^{\text {th }}$ International Congress on aPL considered revisions to the Sapporo criteria, and the Sydney revised Sapporo criteria for definite APS were proposed ${ }^{11}$. The revised criteria provide definitions of the features in APS patients that were not included in the Sapporo criteria. Also, in the revised criteria IgG/IgM anti- $\beta 2 \mathrm{GPI}$ antibodies (a $\beta 2 \mathrm{GPI}$ ) are listed together with aCL and LA to categorize APS.

The aim of this study was to analysis the clinical and immunological manifestations of APS, according to the Sydney revised Sapporo criteria for APS classification, in a cohort of Japanese patients recruited in a single center. All the patients were followed-up, the prevalence of APS manifestations and the profile of aPL during the study period were evaluated. 


\section{Patients and Methods}

\section{Patients}

This study is a retrospective cohort study of Japanese patients with APS. The study was conducted in one single center at Hokkaido University Hospital in Sapporo.

The autoimmune disease database of the autoimmune outpatient clinic was queried for diagnosis of APS registered between $1^{\text {st }}$ January 1988 and $31^{\text {st }}$ December 2010. A retrospective review of the clinical charts of the APS patients was performed and the diagnosis of APS according to the Sydney revised Sapporo criteria for definite APS ${ }^{11}$ verified by the authors. The historical profile of thrombotic manifestations, obstetric complications and laboratory findings from each visit was obtained by the authors using medical records. The coexistence of systemic lupus erythematosus (SLE) was diagnosed according to the American College of Rheumatology (ACR) revised criteria ${ }^{12}$.

On the first visit all the patients were interviewed and underwent a general physical examination by a qualified rheumatologist. Serum and plasma samples from each patient were collected for initial laboratories studies. The patient's clinical examination and laboratory findings on the follow-up visits to the outpatient clinic were obtained from the medical records. The study was conducted in accordance with the Declaration of Helsinki and the principles of good clinical practice. 


\section{Clinical Manifestations}

The presence of arterial thrombosis was confirmed by brain magnetic resonance imaging (MRI), angiography and computed tomography scan. Ischemic heart disease including myocardial infarction and angina was confirmed by electrocardiographic changes, increased cardiac enzymes and coronary angiography. Venous thrombosis was confirmed by radio isotope (RI) venography, doppler ultrasound, flebography, lung perfusion scintigraphy or retinal fluorescence. Pregnancy morbidity was defined according to the Sydney revised Sapporo criteria ${ }^{11}$.

Information about the following risk factors for arterial thrombosis was obtained from the medial records. Current cigarette smoking was defined as smoking. Patients were classified as having hypertension if they used antihypertensive medication, had a systolic blood pressure $\geqq$ $140 \mathrm{mmHg}$ or had a diastolic blood pressure $\geqq 90 \mathrm{mmHg}$. Dyslipidemia was defined as the use of lipid-lowering agents or an elevated serum low-density lipoprotein concentration above $140 \mathrm{mg} / \mathrm{dl}$. Diabetes was defined as the use of antidiabetic medication or an increased levels of hemoglobin $\mathrm{A} 1 \mathrm{C}>6.5 \%$. Steroid treatment was defined as the use of any oral or intravenous corticosteroid therapy. The use of other drugs including anti-platelet agents, statins and anticoagulant therapy was also recorded. 


\section{Laboratory investigations}

Venous blood was collected in tubes containing $1 / 10$ volume of $0.105 \mathrm{M}$ sodium citrate and was centrifuged immediately at $4^{\circ} \mathrm{C}$. Plasma samples were depleted of platelets by filtration then stored at $-80^{\circ} \mathrm{C}$ until they were used.

The presence of aPL was evaluated in all the patients at the first visit and at least 12 weeks apart. Anticardiolipin antibodies (IgG and IgM) were assayed according to the standard ELISA ${ }^{13}$.

For the detection of LA, clotting tests were performed using a semiautomated hemostasis analyzer (STart 4; Diagnostica Stago) and the previous version of the guidelines recommended by the Subcommitte on LA /aPL of the Scientific and Standardisation Committee of the International Society of Thrombosis and Haemostasis (SSC-ISTH) were followed ${ }^{3}$. For measurement of the activated Partial Thromboplastin Time (aPTT), a sensitive reagent with low phospholipid concentration (test PTT-LA; Diagnostica Stago) was used for screening and mixing test, and the results were confirmed with the use of a Staclot LA kit (Diagnostica Stago). The Dilute Russell's viper venom time (dRVVT) was screened and confirmed by use of a Gradipore LA test (Sydney New South Wales, Australia). The kaolin clotting time (KCT) was measured using a kaolin solution (Dade Behring, Liederbach, Germany) with the standard protocol. The cut-off levels for the LA tests were previously established as $>99^{\text {th }}$ percentile of 40 healthy subjects, as our routine laboratory assays. 
IgG and IgM aß2GPI were determined by ELISA as previously reported ${ }^{14}$. Briefly, irradiated microtiter plates were coated with $4 \mu \mathrm{g} / \mathrm{ml}$ of purified $\beta$ 2GPI (Yamasa Corp. Tokyo, Japan) in phosphate-buffered saline (PBS) at $4^{0} \mathrm{C}$ and washed with PBS. Wells were blocked with $3 \%$ gelatin (BDH Chemicals Ltd, Poole, washed with PBS 0.05\% Tween 20 (Sigma Chemical Co., St Louis, MO, USA) (PBS-Tween) and $50 \mu \mathrm{l}$ of serum 1:50 diluted with PBS containing 1\% bovine serum albumin (Sigma) (PBS-1\% BSA) were added in duplicate. Plates were incubated for 1 hour at room temperature, washed and the appropriate dilution of alkaline phosphatase (ALP)-conjugated goat anti-human IgG and IgM (Sigma) in PBS-1\%BSA was added. After 1 hour of incubation at room temperature and four washes, $100 \mu \mathrm{l} /$ well of $1 \mathrm{mg} / \mathrm{ml}$-nitrophenylphosphate disodium (Sigma) in $1 \mathrm{M}$ diethanolamine buffer ( $\mathrm{pH}$ 9.8) were added. Following colour development, optical density (OD) at $405 \mathrm{~nm}$ was measured by a Multiskan ascent plate reader. Normal ranges of IgG and IgM ab2GPI with cut-off values of 99th percentile were previously established using 132 healthy controls.

IgG and IgM phosphatidylserine-dependent antiprothrombin antibodies (aPS/PT) were evaluated by an in-house ELISA using the phosphatidylserine/prothrombin complex as antigen 15, Non-irradiated microtiter plates (Sumilon type S, Sumitomo Bakelite, Tokyo, Japan) were coated with $50 \mu \mathrm{g} / \mathrm{ml}$ of phosphatidylserine (Sigma), and dried overnight at $4^{\circ} \mathrm{C}$. Wells were blocked with $150 \mu \mathrm{l}$ of Tris-buffered saline (TBS) containing $1 \%$ fatty-acid free BSA and $5 \mathrm{mM} \mathrm{CaCl}_{2}(\mathrm{BSA}-\mathrm{Ca})$. After 3 washes in TBS 
0.05\% Tween 20 with $5 \mathrm{mM} \mathrm{CaCl}$ (TBS-Tween-Ca), $50 \mu \mathrm{l}$ of $10 \mu \mathrm{g} / \mathrm{ml}$ human prothrombin (Diagnostica Stago, Asnieres, France) in BSA-Ca were added to half of the wells in the plates and the same volumePS of BSA-Ca alone to the other half. After 1 hour incubation at $37^{\circ} \mathrm{C}$, plates were washed and $50 \mu \mathrm{l}$ of serum diluted in BSA-Ca in 1:100 were added in duplicate. Plates were incubated for 1 hour at room temperature, followed by ALP-conjugated goat anti-human IgG or IgM and substrate. The aPS/PT titer of each sample was derived from the standard curve according to dilutions of the positive control. Normal ranges of IgG and IgM aPS/PT with cut-off values of $99^{\text {th }}$ percentile were previously established using 132 healthy controls.

\section{Statistical analysis}

Statistical evaluation was carried out by Fisher's exact test or chi-square test as appropriate. $\mathrm{P}$ values less than 0.05 were considered significant. Patient characteristics and risk factors were entered into a multivariate logistic regression model to identify variables that independently predicted arterial thrombosis developing. Calculations were made using the statistical software package SPSS statistics (version 18.0). 


\section{Results}

\section{Patients features}

A total of 141 consecutive patients with the diagnosis of APS were recruited. The cohort comprised 119 females and 22 males. Table 1 shows clinical and demographic characteristics in our cohort. Mean age at disease onset was 41.2 years (range 9-79 yrs) and mean age at end of the follow-up was 48.6 years (range 18-87 yrs). Median follow up period was 7 years (range 0-22 yrs). Fifty percent of the APS patients had SLE. The number of patients with hypertension or taking anticoagulation/steroid therapy was higher in patients with SLE compared to those with primary APS. Eight patients with primary APS were on steroid therapy due to arthritis.

\section{Thrombotic events}

Thrombosis was found in 121 patients (85.8\%), arterial thrombosis in 93 and venous thrombosis in 46 (66\% and $32.6 \%$, respectively) (Table 2). Among patients with arterial thrombosis, the most common manifestation was cerebral infarction observed in 86 patients (61.0\%).

Other arterial thrombotic events are summarized in Table 2. Ischemic heart disease, arterial ischemia in legs, mesenteric artery occlusion, splenic infarction, and renal infarction were documented.

The most common thrombotic event in the venous territory was deep vein thrombosis found in $33(23.4 \%)$ patients, followed by pulmonary 
embolism 14 (9.9\%) (Table 2).

During the study period, 34 recurrences of the thrombotic events were observed in 31 patients. Among them, 10 patients (32\%) were on anticoagulation/anti-platelet combination therapy, 9 patients $(29.0 \%)$ on anticoagulation only and $12(38.7 \%)$ on anti-platelet only. Twenty one out of 21 patients $(67.7 \%)$ were taking steroid treatment and $8(25.8 \%)$ statins. Patients on warfarin/anti-platelet combination therapy had a high rate of recurrence compared to those receiving either anticoagulation or anti-platelet. This finding could be explained because patients with high risk of recurrence were those who received more aggressive treatment with combination therapy. Recurrent arterial thrombosis was found in 22 patients $(15.6 \%)$ and recurrent venous thrombosis in 9 (6.4\%). In twenty four patients $(77.4 \%)$ the thrombotic event recurred in the same vascular territory (arterial event recurred in an arterial location and venous event in a venous vessel). Only 3 patients with arterial thrombosis at the disease onset developed a venous thrombotic event during the follow-up, and 4 patients with venous thrombosis had a new thrombotic event in the arterial circulation.

\section{Obstetric complications}

Our cohort includes 70 women who became pregnant during the study period.

Forty-three out 70 pregnant females (61.4\%) had obstetric complications 
defined in the Sydney revised Sapporo criteria for pregnancy morbidity ${ }^{11}$. One or more fetal loss at or beyond the $10^{\text {th }}$ week of gestation was found in 32 females $(45.7 \%)$, one or more premature birth before the 34 week of gestation in $12(17.1 \%)$, and three or more unexplained abortions before the $10^{\text {th }}$ week of gestation in $10(14.3 \%)$ (Table 2$)$.

The total number of pregnancies occurred in 70 pregnant females in our cohort during the study period were 169. We documented 104 pregnancy losses, $54(32.0 \%)$ were early fetal loss that occurred before the 10th week of gestation and $50(29.6 \%)$ were deaths of fetus at or beyond the 10th week of gestation. Fifteen pregnancies (8.9\%) resulted in premature births of a neonate before the 34 week of gestation and $50(29.6 \%, 50 / 169)$ in full term births (Table 2).

Among 169 pregnancies observed in our cohort, 119 (71.4\%) presented with some of the APS-related pregnancy complications described above. Obstetric problems were observed in 45 pregnant females. However, in 25 females, a total of 50 pregnancies developed without any APS-related obstetric problems.

\section{Antiphospholipid antibody profile}

Antiphospholipid antibodies were assayed in all the patients at the first visit and at least 12 weeks apart. Several other evaluation of aPL were performed in the routine visits during the study period.

The prevalence of each evaluated aPL is presented in Table $3 . \quad$ LA 
was the most prevalent aPL detected in 116 patients $(82.3 \%)$. aCL were found in 83 patients $(58.9 \%)$, aß2GPI in $73(51.8 \%)$ and aPS/PT in 98 (69.5\%). There was no correlation between aPL profile and any particular APS manifestations, such as thrombosis or obstetric events.

The aPL profile in the cohort is shown in Figure 1. Twenty six patients (18.4\%) had either LA, aCL or aß2GPI as the sole aPL during the study period. The presence of LA in conjunction with IgG/IgM aCL, IgG/IgM aß2GPI and IgG/IgM aPS/PT was detected in 45 patients (31.9\%) and was the combination more frequently in our cohort. LA and IgG/IgM aPS/PT combination was found in 28 patients (19.9\%).

\section{Comparison of clinical characteristics between patients with or without associated thrombotic risk factors}

Additional risk factors for thrombosis were defined according to the classification proposed in the Sydney revised criteria for definite APS ${ }^{11}$. The presence of thrombosis, arterial thrombosis and stroke was more prevalent in the group of patients with additional risk factors for thrombosis, Odds Ratio (OR), 95\% confidence interval [C.I] 2.81 [1.29-6.44],2.0, [1.29-3.09]and 1.57, [1.05-2.35], respectively ( Table4).

\section{Risk factors of arterial thrombosis}

APS patients were grouped according to the presence or absence of arterial thrombosis. The presence of the above mentioned risk factors for arterial 
thrombosis is shown in Table 5. Age and hypertension represent a risk for having arterial thrombosis in our Japanese APS cohort. The relative risk approximated by OR, 95\% C.I was 1.82, [1.30-2.54] and 3.26 [1.16-9.14] for age by decade and hypertension, respectively.

\section{Discussion}

In this observational study, we retrospectively analyzed the clinical and immunological characteristics of APS in a large cohort of Japanese patients and observed a high incidence of arterial thrombotic events. This is the first large Asian cohort of APS analyzed. The study design enables a detailed and accurate collection of data in a homogenous population.

Antiphospholipid syndrome is a heterogeneous autoimmune disease with several pattern of disease expression as reported in a Caucasoid cohort of patients with APS ${ }^{10}$. This cohort was established in the Euro-phospholipid project with a multicenter and prospective design and comprised 1000 patients. The multicenter design of the study allowed the collection of a large population of APS patients, but has several limitations due the diversity of clinicians involved in the diagnosis and management of patients. Some of the clinical features of APS could not be detected by all the clinicians leading to a low prevalence in the whole cohort. Moreover, the difficulties to standardize positive and negative values for laboratory data represent an additional problem in this type of studies.

We present a single center study in which all the patients were 
recruited in the same autoimmune disease clinic and with all the aPL determination performed in the same laboratory. Our cohort showed a high incidence of arterial thrombotic events. Especially elevated was the rate of cerebral infarction in the Japanese cohort, $61.0 \%$ compared to $19.8 \%$ in the European cohort ${ }^{10}$. There was no correlation between aPL profile and arterial thrombosis in our cohort. In contrast, there was correlation between the presence of additional thrombotic risk factor and arterial thrombosis by univariate analysis (Table4). And as result of a multivariate analysis, hypertension appeared as a risk for arterial thrombosis (Table 5). Ruffatti et al reported hypertension as a risk for the first thrombotic event in aPL carriers by retrospective and prospective cohort studies 16, 17. Previous studies with smaller numbers of patients have also shown the association between hypertension and arterial thrombosis ${ }^{18,19}$. Our data in the Japanese cohort support those previous observations in European and American patients, therefore hypertension would be one of the most important risks for having arterial diseases in patients with aPL beyond races/populations. Blood pressure values are known to be relatively higher in Japanese than in other developed country populations ${ }^{20}$, and might represent one of the plausible explanations of why Japanese APS patients are more prone to have stroke than European APS patients. The prevalence of deep vein thrombosis in Japanese population (23.4\%) was, in contrast, lower than that in European (38.9\%) 10. The prevalence of deep vein thrombosis is also known to be lower in Japanese than other developed country populations 21, 22 . 
Considering the epidemiological characteristic that the Japanese population is more prevalent in arterial thrombosis and less in venous vascular events, it is likely that the genetic and/or environmental background affect to the prevalence of thrombotic events as well in patients with aPL.

We observed a similar incidence between early and late fetal loss in the cumulative obstetric manifestations in 169 pregnancies (32\% had early fetal loss and 29.6\% late fetal loss). The high incidence of late fetal loss in our cohort could be explained in part because our patients were recruited at Hokkaido University Hospital, a referral center for risk pregnancy patients for the whole Hokkaido area. In addition, we observed a high rate of late fetal loss recurrence among 50 patients with late fetal loss. Eleven (22\%) patients with first late fetal loss had recurrent episodes of late fetal loss varying from 2 to 6 times.

Taking together, our observation would support the argument that aPL represents a risk of thrombotic events and/or pregnancy morbidity, rather than as diagnostic tool ${ }^{23-27}$.

Regarding aPL profile, there is a great variety in the methodology for antibody testing among different laboratories which make difficult the comparison of the results. In the Sydney revised Sapporo criteria, both LA and aCL (IgG and IgM) were maintained as laboratory criteria and aß2GPI (IgG and IgM) added. More importantly, the cut-off setting was defined by non-parametric $99^{\text {th }}$ percentile of healthy population in aCL and aß2GPI ELISAs, making the results of the prevalence more comparable among the 
laboratories. Prevalence of aCL (IgG or IgM) and aß2GPI (IgG or M) in the Japanese APS cohort was 58.9\% and 51.8\%, respectively. aCL were less prevalent in our series than in European cohort (88\%) and these variation may be explained, in part, by the methodological or cut-off settings differences among the laboratories.

LA tests used for screening in routine laboratory practice display large differences in sensitivity and responsiveness, according to the reagent, the automated and the procedure employed ${ }^{28}$. Therefore, the SSC-ISTH recommends to use at least two different screening tests ${ }^{3}$. In our study we tested LA using three procedures and found LA in $82.3 \%$ of patients, and in 14 patients $(9.9 \%)$ LA was the only aPL detected

It is already recognized that a $\beta 2 \mathrm{GPI}$ correlated with thrombosis and pregnancy complications ${ }^{29-32}$, although there are still some controversial reports denying these associations. The Sydney revised Sapporo criteria for APS take into account the limitations of aß2GPI as a criterion mainly because of methodological differences and lack of standardization which made difficult the interpretation of the results. We found a prevalence of aß2GPI of $51.8 \%$, including $4(2.8 \%)$ patients in the absence of LA and aCL, with the method being performed for 17 years in our laboratory. Antibodies reacting with $\beta 2 \mathrm{GPI}$ are detected in some patients in the absence of aCL. There are, at least two possible explanations for those findings. First, the target epitopes located on $\beta 2$ GPI for a $\beta 2$ GPI binding are cryptic when $\beta 2$ GPI is combined with cardiolipin in the solid phase assay. These type of a $32 \mathrm{GPI}$ 
in the absence of aCL has been detected in children with atopic dermatitis ${ }^{33}$. The second possibility is related to the cut-off setting. The aCL ELISA detect a lot of non-specific low affinity antibodies in apparently healthy population leading to the setting of a higher cut-off level (99th percentile) compared with aß2GPI cut-off. Therefore, borderline positive a $32 \mathrm{GPI}$ turned negative in the aCL ELISA assay.

Antiprothrombin antibodies attracted the interest of many researchers in the APS field as responsible for the LA activity 7,34 . It is recognized that antiprothrombin antibodies presumably recognize an epitope exposed upon calcium-mediated binding of human prothrombin to phospholipids ${ }^{34}$. Antiprothrombin antibodies are more efficiently detected when prothrombin is bound to phosphatidylserine-coated onto ELISA plates in the presence of calcium, the aPS/PT ELISA ${ }^{35}$. The clinical significance of antiprothrombin antibodies has not yet been elucidated ${ }^{36}$, but aPS/PT showed higher correlation with venous and arterial thrombosis, and LA ${ }^{15}$. As well as $\beta 2$ GPI-dependent aCL, aPS/PT had high sensitivity and specificity for the diagnosis of APS and are considered useful tools for the diagnosis of $\mathrm{APS}^{37}$. According to our previous observation, we investigated the prevalence of antiprothrombin antibodies by the aPS/PT ELISA. In our cohort, the prevalence of aPS/PT was higher than that of aCL $(68.8 \%$ vs. $58.9 \%)$ supporting the possibility of its usefulness as a marker of APS.

In conclusion, this single center Japanese APS cohort shows the analysis of the clinical and immunological feature of Japanese APS patients. 
The characteristic of clinical manifestations in Japanese APS would represent the profile of general Japanese population, therefore it is likely that not only aPL but a number of genetic/environmental factors play roles to develop the syndrome.

\section{Acknowledgments}

We thank Miki Aoto for her technical support in the performance of laboratory tests. This work was supported by the Japanese Ministry of Health, Labour and Welfare, and the Japanese Ministry of Education, Culture, Sports, Science and Technology (MEXT). Olga Amengual is funded by MEXT and the Japanese Society for the Promotion of the Science (project number 21-40106). 


\section{References}

1. Atsumi T, Amengual O and Koike T. Antiphospholipid Syndrome: Pathogenesis. In: Lahita RG, (ed.). SYSTEMIC LUPUS ERYTHEMATOSUS. 5 ed. San Diego: Academic press, 2011, p. 945-65.

2. Harris EN, Gharavi AE, Boey ML, et al. Anti-cardiolipin antibodies: Detection by radioimmunoassay and association with thrombosis in systemic lupus erythematosus. Lancet. 1983; ii: 1211-4.

3. Brandt JT, Triplett DA, Alving B and Scharrer I. Criteria for the diagnosis of lupus anticoagulants: an update. On behalf of the Subcommittee on Lupus Anticoagulant/Antiphospholipid Antibody of the Scientific and Standardisation Committee of the ISTH. Thromb Haemost. 1995; 74: 1185-90.

4. Galli M, Comfurius P, Maassen C, et al. Anticardiolipin antibodies (ACA) directed not to cardiolipin but to a plasma protein cofactor. Lancet. 1990; 335: 952-3. 5. Matsuura E, Igarashi $\mathrm{Y}$, Fujimoto $\mathrm{M}$, Ichikawa $\mathrm{K}$ and Koike $\mathrm{T}$. Anticardiolipin cofactor(s) and differential diagnosis of autoimmune disease. Lancet. 1990; $336: 177-8$.

6. McNeil HP, Simpson RJ, Chesterman CN and Krilis SA. Anti-phospholipid antibodies are directed against a complex antigen that induces a lipid-binding inhibitor of coagulation: $\beta 2$-glycoprotein I (apolipoprotein H). Proc Natl Acad Sci USA. 1990; 87: 4120-4.

7. Bevers EM, Galli M, Barbui T, Comfurius $\mathrm{P}$ and Zwaal RF. Lupus anticoagulant IgG's (LA) are not directed to phospholipids only, but to a complex of lipid-bound human prothrombin. Thromb Haemost. 1991; 66: 629-32. 
8. Hughes GR. Thrombosis, abortion, cerebral disease, and the lupus anticoagulant. Br Med J (Clin Res Ed). 1983; 287: 1088-9.

9. Wilson WA, Gharavi AE, Koike T, et al. International consensus statement on preliminary classification criteria for definite antiphospholipid syndrome: report of an international workshop. Arthritis Rheum. 1999; 42: 1309-11.

10. Cervera R, Piette JC, Font J, et al. Antiphospholipid syndrome: clinical and immunologic manifestations and patterns of disease expression in a cohort of 1,000 patients. Arthritis Rheum. 2002; 46:1019-27.

11. Miyakis S, Lockshin MD, Atsumi T, et al. International consensus statement on an update of the classification criteria for definite antiphospholipid syndrome (APS). J Thromb Haemost. 2006; 4: 295-306.

12. Tan EM, Cohen AS, Fries JF, et al. The 1982 revised criteria for the classification of systemic lupus erythematosus. Arthritis Rheum. 1982; 25: 1271-7.

13. Harris EN, Gharavi AE, Patel BM and Hughes GRV. Evaluation of the anti-cardiolipin antibody test: report of an international workshop held 4 April 1986. Clin Exp Immunol. 1987; 68: 215-22.

14. Amengual O, Atsumi T, Khamashta MA, Koike $\mathrm{T}$ and Hughes GR. Specificity of ELISA for antibody to beta 2-glycoprotein I in patients with antiphospholipid syndrome. Br J Rheumatol. 1996; 35: 1239-43.

15. Atsumi T, Ieko M, Bertolaccini ML, et al. Association of autoantibodies against the phosphatidylserine-prothrombin complex with manifestations of the antiphospholipid syndrome and with the presence of lupus anticoagulant. Arthritis Rheum. 2000; 43: 1982-93.

16. Ruffatti A, Del Ross T, Ciprian M, et al. Risk factors for a first thrombotic event in antiphospholipid antibody carriers: a prospective multicentre follow-up 
study. Ann Rheum Dis. 2011; 70: 1083-6.

17. Ruffatti A, Del Ross T, Ciprian M, et al. Risk factors for a first thrombotic event in antiphospholipid antibody carriers. A multicentre, retrospective follow-up study. Ann Rheum Dis. 2009; 68: 397-9.

18. Erkan D, Yazici Y, Peterson MG, Sammaritano L and Lockshin MD. A cross-sectional study of clinical thrombotic risk factors and preventive treatments in antiphospholipid syndrome. Rheumatology (Oxford). 2002; 41: 924-9.

19. Danowski A, de Azevedo MN, de Souza Papi JA and Petri M. Determinants of risk for venous and arterial thrombosis in primary antiphospholipid syndrome and in antiphospholipid syndrome with systemic lupus erythematosus. $J$ Rheumatol. 2009; 36: 1195-9.

20. Mtabaji JP, Moriguchi Y, Nara Y, Mizushima S, Mano M and Yamori Y. Ethnic differences in salt sensitivity: genetic or environmental factors? Clin Exp Pharmacol Physiol Suppl. 1992; 20: 65-7.

21. Sakuma M, Nakamura M, Yamada N, et al. Venous thromboembolism: deep vein thrombosis with pulmonary embolism, deep vein thrombosis alone, and pulmonary embolism alone. Circ J. 2009; 73: 305-9.

22. Fowkes FJ, Price JF and Fowkes FG. Incidence of diagnosed deep vein thrombosis in the general population: systematic review. Eur J Vasc Endovasc Surg. 2003; $25: 1-5$.

23. Roubey RA. Risky business: the interpretation, use, and abuse of antiphospholipid antibody tests in clinical practice. Lupus. 2010; 19: 440-5.

24. Urbanus RT, Siegerink B, Roest M, Rosendaal FR, de Groot PG and Algra A. Antiphospholipid antibodies and risk of myocardial infarction and ischaemic stroke in young women in the RATIO study: a case-control study. Lancet Neurol. 2009; 8: 
998-1005.

25. Naess IA, Christiansen SC, Cannegieter SC, Rosendaal FR and Hammerstroem J. A prospective study of anticardiolipin antibodies as a risk factor for venous thrombosis in a general population (the HUNT study). $J$ Thromb Haemost. 2006; 4: 44-9.

26. de Groot PG, Lutters B, Derksen RH, Lisman T, Meijers JC and Rosendaal FR. Lupus anticoagulants and the risk of a first episode of deep venous thrombosis. J Thromb Haemost. 2005; 3: 1993-7.

27. Otomo K, Atsumi T, Amengual O, et al. Efficacy of the antiphospholipid score for the diagnosis of antiphospholipid syndrome and its predictive value for thrombotic events. Arthritis Rheum. 2012; 64: 504-12.

28. Exner T, Hohnen-Behrens C, Newman $\mathrm{P}$ and Dargan W. Effect of instruments on lupus anticoagulant testing. Thromb Haemost. 2000; 83: 345-8.

29. Galli M, Luciani D, Bertolini G and Barbui T. Anti-beta 2-glycoprotein I, antiprothrombin antibodies, and the risk of thrombosis in the antiphospholipid syndrome. Blood. 2003; 102: 2717-23.

30. Reber G, Tincani A, Sanmarco M, de Moerloose P and Boffa MC. Proposals for the measurement of anti-beta2-glycoprotein I antibodies. Standardization group of the European Forum on Antiphospholipid Antibodies. J Thromb Haemost. 2004; 2: $1860-2$.

31. Faden D, Tincani A, Tanzi P, et al. Anti-beta 2 glycoprotein I antibodies in a general obstetric population: preliminary results on the prevalence and correlation with pregnancy outcome. Anti-beta2 glycoprotein I antibodies are associated with some obstetrical complications, mainly preeclampsia-eclampsia. Eur J Obstet Gynecol Reprod Biol. 1997; 73: 37-42. 
32. Lee RM, Branch DW and Silver RM. Immunoglobulin A anti-beta2-glycoprotein antibodies in women who experience unexplained recurrent spontaneous abortion and unexplained fetal death. Am J Obstet Gynecol. 2001; 185: $748-53$.

33. Ambrozic A, Avicin T, Ichikawa K, et al. Anti-beta(2)-glycoprotein I antibodies in children with atopic dermatitis. Int Immunol. 2002; 14: 823-30.

34. Arvieux J, Darnige L, Caron C, Reber G, Bensa JC and Colomb MG. Development of an ELISA for autoantibodies to prothrombin showing their prevalence in patients with lupus anticoagulants. Thromb Haemost. 1995; 74: $1120-5$.

35. Galli M, Beretta G, Daldossi M, Bevers EM and Barbui T. Different anticoagulant and immunological properties of anti-prothrombin antibodies in patients with antiphospholipid antibodies. Thromb Haemost. 1997; 77: 486-91.

36. Galli $\mathrm{M}$ and Barbui T. Antiprothrombin antibodies: detection and clinical significance in the antiphospholipid syndrome. Blood. 1999; 93: 2149-57.

37. Atsumi T and Koike T. Antiprothrombin antibody: why do we need more assays? Lupus. 2010; 19: 436-9. 


\section{Figure Legends}

\section{Figure1 Distribution of aPL in the Japanese APS cohort.}

Positivity for all four aPL, LA in conjunction with IgG/IgM aCL, IgG/IgM a $32 \mathrm{GPI}$ and IgG/IgM aPS/PT, was the profile of aPL most frequent found in our cohort, detected in 45 patients $(31.9 \%)$. The second most frequent profile of aPL was the presence of LA in conjunction with IgG/IgM aPS/PT that was detected in 28 patients (19.9\%). Twenty six patients (18.4\%) had either LA, aCL or aß2GPI as the sole aPL during the study period. Presence of two aPL was observed in 45 patients (31.9\%) and 3 aPL in 25 patients (17.7\%).

aPL: antiphospholipid antibodies, LA : Lupus anticoagulant positive , aCL : IgG and/ or IgM anticardiolipin antibodies positive, ab2GPI: IgG and/ or IgM anti-62glycoprotein I antibodies positive, aPS/PT : IgG and/ or IgM phosphatidylserine-dependent antiprothrombin antibodies positive. 


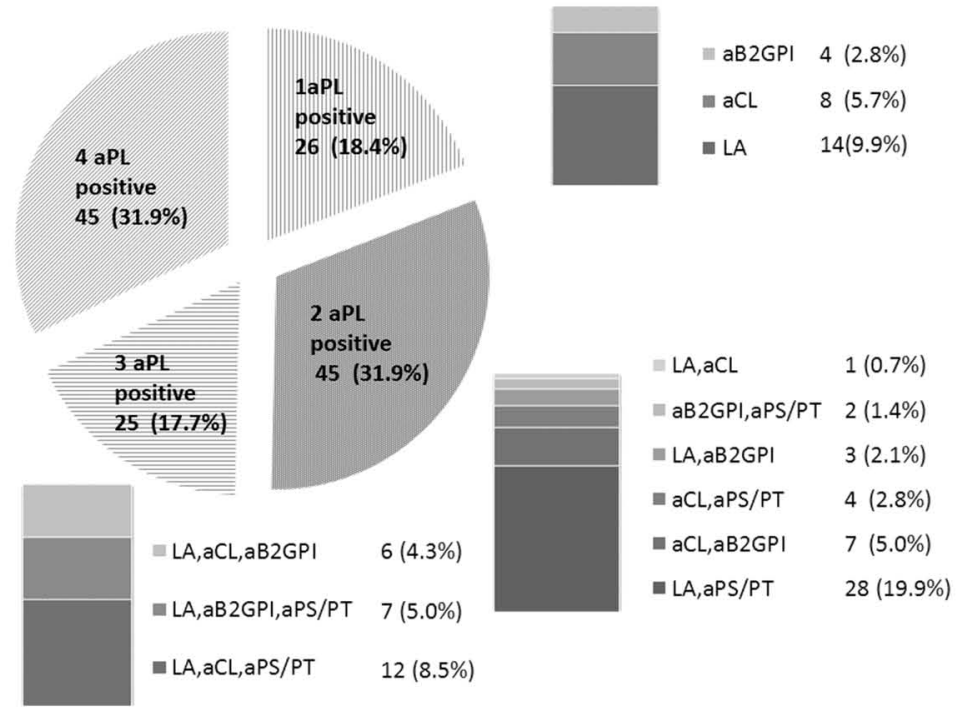


Table 1. Clinical and demographic characteristics in the Japanese APS cohort

\begin{tabular}{|c|c|c|c|c|c|c|c|}
\hline \multirow[b]{2}{*}{ Number (\%) } & \multicolumn{2}{|c|}{ All } & \multicolumn{2}{|c|}{ Primary APS } & \multicolumn{2}{|c|}{ SLE with APS } & \multirow{2}{*}{$\begin{array}{c}\text { P value } \\
\text { N.S. }\end{array}$} \\
\hline & 141 & $(100)$ & 70 & $(49.6)$ & 71 & $(50.1)$ & \\
\hline Female $(\%)$ & 119 & $(84.4)$ & 58 & $(82.9)$ & 61 & $(85.9)$ & N.S. \\
\hline Mean age at disease onset (range): years & 41.2 & $(9-79)$ & 43.1 & $(9-79)$ & 39.3 & $(11-70)$ & N.S. \\
\hline Mean age at end of follow up (range): years & 48.6 & $(18-87)$ & 49.2 & $(18-87)$ & 48.0 & $(20-77)$ & N.S. \\
\hline Median follow up period (range): years & 7 & $(0-22)$ & 6 & $(0-15)$ & 8 & $(0-22)$ & 0.003 \\
\hline Smoking (\%) & 47 & $(33.3)$ & 23 & $(32.9)$ & 24 & $(33.8)$ & N.S. \\
\hline Hypertension (\%) & 49 & $(34.8)$ & 15 & $(21.4)$ & 34 & $(47.9)$ & 0.002 \\
\hline Dyslipidemia (\%) & 46 & $(32.6)$ & 17 & $(24.3)$ & 29 & $(40.8)$ & N.S. \\
\hline Diabetes Mellitus (\%) & 18 & $(12.8)$ & 7 & $(10.0)$ & 11 & $(15.5)$ & N.S. \\
\hline Body mass index $\quad( \pm \mathrm{S} . \mathrm{D}): \mathrm{kg} / \mathrm{m}^{2}$ & 23.0 & $(5.0)$ & 24.6 & $(6.9)$ & 22.7 & $(3.5)$ & N.S. \\
\hline Steroid treatment (\%) & 79 & $(56.0)$ & 8 & $(11.4)$ & 71 & $(100)$ & $<0.001$ \\
\hline Anti-platelet (\%) & 61 & $(43.3)$ & 34 & $(48.6)$ & 27 & $(38.0)$ & N.S. \\
\hline Oral anti-coagulation (\%) & 79 & $(56.0)$ & 29 & $(41.4)$ & 50 & $(70.4)$ & $<0.001$ \\
\hline Statins $(\%)$ & 20 & $(14.2)$ & 6 & $(8.6)$ & 14 & (19.7) & N.S. \\
\hline
\end{tabular}

APS: Antiphospholipid syndrome, SLE: Systemic lupus erythematosus, N.S.: not statistically significant Anti-platelet including aspirin, clopidogrel, ticlopidine, cilostazol and dipyridamole 
Table 2. Prevalence of the cumulative events

\begin{tabular}{|c|c|c|}
\hline \multirow{2}{*}{$\begin{array}{l}\text { Manifestation } \\
\text { Thrombosis }\end{array}$} & \multicolumn{2}{|c|}{ Number (\% of the total cohort) } \\
\hline & 121 & $(85.8)$ \\
\hline Arterial thrombosis & 93 & $(66.0)$ \\
\hline Cerebral infarction & 86 & $(61.0)$ \\
\hline Ischemic heart disease & 6 & $(4.3)$ \\
\hline Arterial ischemia in legs & 3 & $(2.1)$ \\
\hline Mesenteric artery occlusion & 3 & $(2.1)$ \\
\hline Splenic infarction & 1 & $(0.7)$ \\
\hline Renal infarction & 1 & $(0.7)$ \\
\hline Venous thrombosis & 46 & $(32.6)$ \\
\hline Deep vein thrombosis & 33 & $(23.4)$ \\
\hline Pulmonary embolism & 14 & $(9.9)$ \\
\hline Superficial thrombophlebitis & 4 & $(2.8)$ \\
\hline Central retinal vein occlusion & 2 & $(1.4)$ \\
\hline Obstetric complications & 45 & $(64.3)$ \\
\hline Pregnant females & 70 & $(58.8)$ \\
\hline Late fetal loss ( $\geqq 10$ weeks) & 32 & $(45.7)$ \\
\hline Premature birth (> 34 weeks) & 12 & $(17.1)$ \\
\hline Recurrent abortions ( $<10$ weeks)\# & 10 & (14.3) \\
\hline
\end{tabular}

Cumulative obstetric manifestations in 169 pregnancies

$\begin{array}{lcc}\text { Early fetal loss }(<10 \text { weeks }) & 54 \\ \text { Late fetal loss }(\geqq 10 \text { weeks }) & 50 \\ \text { Premature birth }(>34 \text { weeks }) & 15 \\ \text { Live birth (full term births) } & 50\end{array}$

※ome patients have more than one condition \#: $\geqq 3$ spontaneous abortions 
Table 3. Antiphospholipid antibody profile

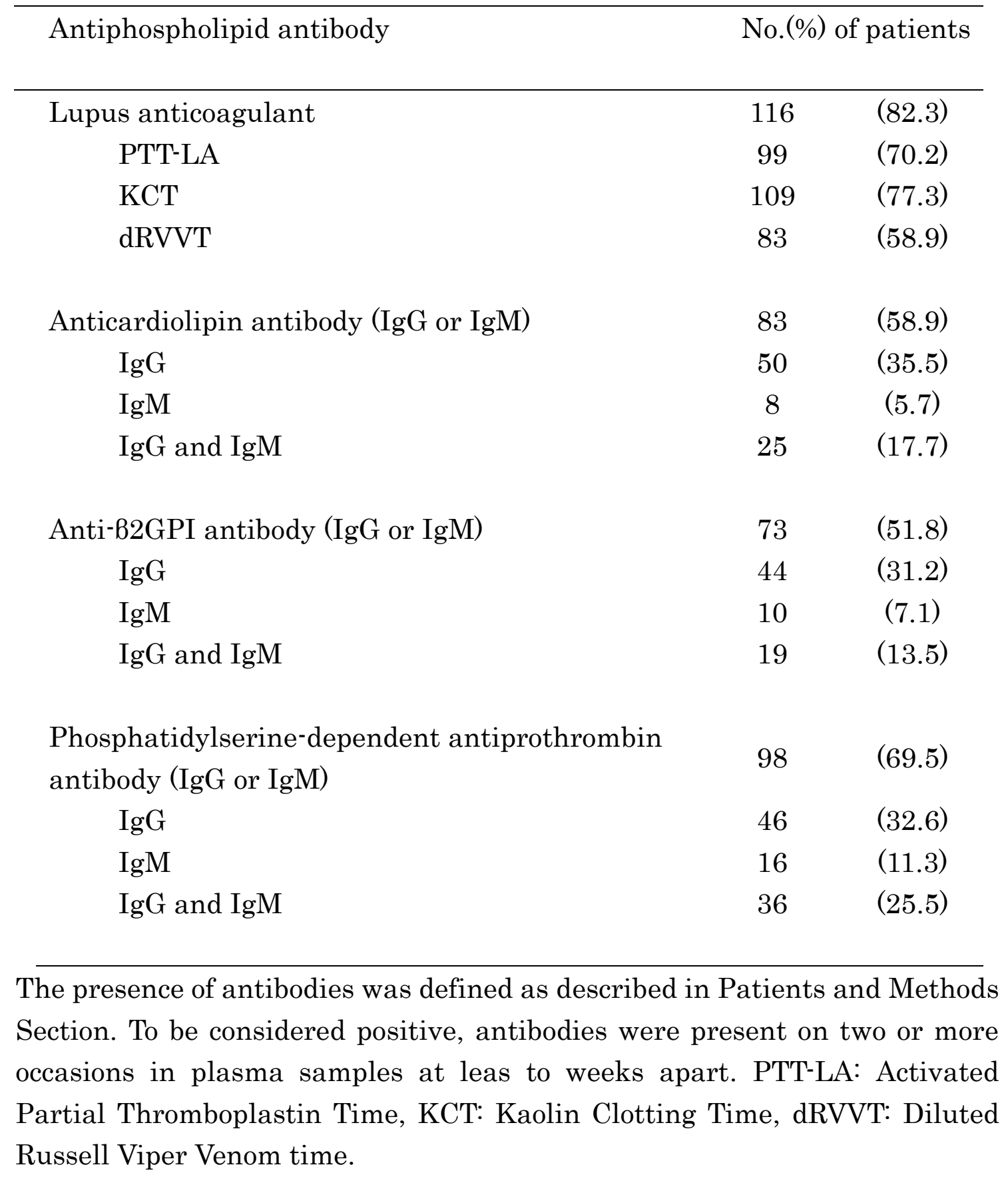


Table 4. Comparison of patients' characteristics in the presence or absence of associated risk factors for thrombosis

\begin{tabular}{|c|c|c|c|c|c|c|c|}
\hline \multirow[t]{2}{*}{ Characteristics } & \multicolumn{2}{|c|}{$\begin{array}{c}\text { Absence of } \\
\text { additional thrombotic } \\
\text { risk factors }{ }^{*} \\
(n=42)\end{array}$} & \multicolumn{2}{|c|}{$\begin{array}{c}\text { Presence of } \\
\text { additional thrombotic } \\
\text { risk factors } \\
(n=99)\end{array}$} & \multirow[t]{2}{*}{$O R$} & \multirow[t]{2}{*}{$95 \% C . I$} & \multirow[t]{2}{*}{$P$ value } \\
\hline & $\mathrm{N}$ & $\%$ & $\mathrm{~N}$ & $\%$ & & & \\
\hline All thrombosis & 31 & $(73.8)$ & 90 & $(90.9)$ & 2.81 & $1.29-6.44$ & 0.015 \\
\hline Arterial thrombosis & 20 & $(47.6)$ & 73 & $(73.7)$ & 2.00 & $1.29-3.09$ & 0.004 \\
\hline Stroke & 20 & $(47.6)$ & 66 & $(66.7)$ & 1.57 & $1.05-2.35$ & 0.039 \\
\hline Ischemic heart disease & 0 & $(0)$ & 6 & $(6.1)$ & 1.07 & $1.01-1.12$ & 0.18 \\
\hline Others & 1 & $(2.4)$ & 6 & $(6.1)$ & 1.04 & $0.97-1.11$ & 0.67 \\
\hline Venous thrombosis & 13 & $(31.0)$ & 33 & $(33.3)$ & 1.04 & $0.81-1.32$ & 0.84 \\
\hline Deep vein thrombosis & 10 & $(23.8)$ & 18 & $(18.2)$ & 0.93 & $0.77-1.13$ & 0.49 \\
\hline Pulmonary embolism & 1 & $(2.4)$ & 8 & $(8.1)$ & 1.06 & $0.99-1.15$ & 0.28 \\
\hline Others & 2 & $(4.8)$ & 4 & $(4.0)$ & 0.99 & $0.92-1.07$ & 1.00 \\
\hline
\end{tabular}

*risk factors defined according to the classification proposed in the Sydney revised Sapporo criteria for definite antiphospholipid syndrome ${ }^{11}$ 
Table 5. Demographic characteristics and antiphospholipid antibody profile in patients with arterial thrombosis and those without

\begin{tabular}{lcccccc}
\hline Characteristic & $\begin{array}{c}\text { Arterial } \\
\text { thrombosis } \\
(n=93)\end{array}$ & $\begin{array}{c}\text { No arterial } \\
\text { thrombosis } \\
(n=48)\end{array}$ & $\begin{array}{c}\text { Adjusted } \\
\text { OR }\end{array}$ & 95\%C.I \\
\hline & $\mathrm{N}$ & $\%$ & $\mathrm{~N}$ & $\%$ & & \\
Age by decade & - & - & - & - & 1.82 & $1.30-2.54$ \\
Women & 76 & $(81.7)$ & 43 & $(89.6)$ & 0.43 & $0.13-1.46$ \\
Steroid & 59 & $(63.4)$ & 20 & $(42.6)$ & 2.03 & $0.82-5.03$ \\
Smoking & 31 & $(33.3)$ & 15 & $(31.2)$ & 1.16 & $0.44-2.86$ \\
Hypertension & 42 & $(45.2)$ & 8 & $(16.7)$ & 3.26 & $1.16-9.14$ \\
Dyslipidemia & 36 & $(38.7)$ & 11 & $(22.9)$ & 0.85 & $0.31-2.34$ \\
Diabetes Mellitus & 15 & $(16.1)$ & 4 & $(8.3)$ & 1.02 & $0.26-4.05$ \\
LA positive & 83 & $(89.2)$ & 41 & $(85.4)$ & 2.87 & $0.62-13.3$ \\
aCL positive & 53 & $(57.0)$ & 32 & $(66.7)$ & 0.74 & $0.23-2.37$ \\
ab2GPI positive & 55 & $(59.1)$ & 27 & $(56.3)$ & 1.70 & $0.58-5.04$ \\
aPS/PT positive & 63 & $(67.7)$ & 35 & $(72.9)$ & 0.52 & $0.17-1.62$
\end{tabular}

LA: Lupus anticoagulant, aCL: IgG and/ or IgM anticardiolipin antibodies, a62GPI: IgG and/ or IgM anti-62glycoprotein I antibodies, aPS/PT: IgG and/ or IgM phosphatidylserine-dependent antiprothrombin antibodies. The presence of smoking, steroid treament, hypertension, dyslipidemia and Diabete Mellitus were defined according to the definition in the Method Section. 